\title{
IMAGEN CORPORAL FEMENINA Y PUBLICIDAD EN REVISTAS
}

\author{
Zaida Salazar Mora*
}

RESUMEN

La mujer actual vive una problemática con respecto a su imagen física, la cual se refleja en una insatisfacción corporal generadora de trastornos alimenticios. Lo anterior es motivado, en alguna medida, por las modelos de cuerpos delgados que presentan los medios de comunicación, por ejemplo, en la Revista Perfil, a manera de estrategia publicitaria, aparecen modelos delgadas como una técnica de persuasión en los anuncios de productos para embellecer.

PALABRAS CLAVES: PUBLICIDAD * IMAGEN CORPORAL * CULTURA * ESTEREOTIPOS * MUJERES * HOMBRES

\section{ABSTRACT}

Women today live a problem regarding their physical image, which is reflected in a corporal dissatisfaction that generates eating habits dysfunctions. The distasted self image and its resulting heath problems are motivated, in some measure, by the thin bodies of models presented by the media. For example, "Perfil" (a fashion magazine) displays thin models as persuasive advertising technique for make up products.

KEY WORDS: PUBLICITY $*$ CORPORAL IMAGE $*$ CULTURE $*$ STEREOTYPE $*$ WOMEN * MEN

\section{INTRODUCCIÓN}

Durante las últimas décadas, se ha experimentado un cambio en la valoración de las dimensiones corporales femeninas. El modelo de belleza corporal ideal se caracteriza por un cuerpo delgado, principalmente en los países y clases sociales donde no existe problema para obtener el alimento. Este patrón estético corporal es establecido y compartido socialmente; por consiguiente, ejerce una presión sobre la población. Según Toro y Vilardel (1987), las mujeres que encarnan las características del modelo delgado ("tubular") tienen razones para autovalorarse positivamente, mientras tanto, quienes se apartan de él muestran insatisfacción corporal y suelen padecer de una baja autoestima. 
A pesar de que esta problemática se acentúa en las últimas décadas, desde 1889 se empieza a reconocer la preocupación por el cuerpo y la delgadez como un problema de salud. Charcot observó el comportamiento de una paciente quien utilizaba un lazo rosa en su cintura y le explicaba que era para asegurarse de no estar ganando peso, porque prefería la muerte a estar gorda (García, 2004). El problema de la imagen corporal ha ido aumentando hasta generar alteraciones graves en la conducta alimenticia, tales como la anorexia y la bulimia. La primera es un desorden que potencialmente puede quitar la vida, caracterizado por el rechazo a comer suficiente para mantener el peso corporal sobre el mínimo, presenta un miedo intenso de engordar, molestia sobre la imagen corporal y, en el caso de las mujeres, una eventual cesación temporal de la menstruación (amenorrea). La bulimia, asimismo, es un desorden caracterizado por la ingesta de grandes cantidades de comida en discretos intervalos de tiempo; sin embargo, esta ingerencia abundante de calorías es expulsada enseguida a través del vómito, la utilización de laxantes o severas dietas restrictivas o la práctica severa de ejercicios (Harrison y Cantor, 1997).

La imagen corporal se refiere a la representación mental que creamos del tamaño, la figura y las partes de nuestro cuerpo, así como, a la percepción que los demás tienen de él. Esta representación no necesariamente coincide con la apariencia física real y puede existir insatisfacción con la imagen corporal, especialmente en las mujeres; no obstante, esta ha aumentado en los hombres. Ellas se sienten más conformes con su cuerpo si están delgadas y las partes de mayor preocupación son el abdomen, las nalgas, los muslos y las caderas (García, 2004).

Los modelos culturales estéticos son más inflexibles en el caso de las mujeres que en los hombres, pues, en las primeras, la valoración del atractivo físico es el indicador más importante de su autoconcepto, tienden a experimentar las modas y la estética predominante en la cultura que valora la delgadez como atractivo físico; además, fomenta el cultivo del cuerpo como una forma de éxito y de aceptación social. Estas valoraciones afectan negativamente la salud de la mujer (García, 2004).
Es decir, cuando la mujer establece la delgadez como un valor altamente positivo, o un modelo corporal a imitar tiende a experimentar un sentimiento de triunfo, éxito y control sobre sí misma. Por el contrario, no ser delgada implica fracasar, ser diferente, no agradar ni estar satisfecha; el no lograr la meta deseada aunque lo intente con esmero provoca un sentimiento de frustración (Toro y Vilardel, 1987).

Las teorías socioculturales de la imagen corporal sugieren que el descontento con el físico se debe a ideales de belleza irrealistas $y$ una de las formas de transmitir estos ideales es a través de los medios de comunicación masivos (Hargreaves y Tiggemann, 2004). Esta normativa sociocultural de la belleza y estética del cuerpo se ve reflejada en los medios a través de modelos expuestos, los cuales las personas tienden a asumirlos como imágenes verdaderas e identificables. Se da así un proceso dinámico e interactivo entre el medio y la recepción. Los medios reflejan la opinión o juicio que, de algún modo, tienden a ser predominantes en la sociedad (Bandura, 1996, en el compendio de Bryant y Zillmann, 1996).

Hargreaves y Tiggemann (2004) consideran que el estándar de belleza es transmitido a los individuos por diferentes fuentes como la familia, el grupo de pares y los medios de comunicación masiva. Asimismo, citan diversidad de investigaciones donde concluyen que las mujeres quienes leen más revistas y ven más televisión reportan mayor insatisfacción con su cuerpo (Anderson y otros, 2001; Botta, 1999; Field y cols, 1999; Harrison 2000, 2001; Hofchire y Greenberg, 2002; Levine y otros, 1994; en Hargreaves y Tiggemann, 2004).

Toro y Vilardel (1987) afirman que la publicidad comercial se ha aprovechado de la importancia del estereotipo de cuerpo delgado para ampliar los mercados. Consideran que los medios presentan imágenes, fotografías, reportajes de salud, datos íntimos de las mujeres famosas y literatura pro adelgazante, que contribuyen al estado de opinión y evaluación que fomenta una imagen corporal delgada; generando un enorme mercado de productos $y$ recursos que real o supuestamente facilitan el adelgazamiento. De manera similar Pearson, Turner y Todd-Mancillas (1993) reconocen que 
los medios de comunicación masiva son instrumentos influyentes en la autoimagen del individuo.

Según Raich, Mora y Soler (1995), citados por García (2004) la insatisfacción corporal es una condición común en la sociedad actual, pues se caracteriza por glorificar la salud, la belleza y la juventud. El anhelo por conseguir un cuerpo delgado puede provocar un gran trastorno emocional e interferir en la vida diaria, especialmente, de mujeres $y$ adolescentes; lo anterior, a causa en parte por lo medios de comunicación, la publicidad, la presión social y la imitación.

\section{ESTUDIOS SOBRE INSATISFACCIÓN CORPORAL Y MEDIOS}

Esta problemática de la insatisfacción corporal ha sido muy investigada en los últimos tiempos principalmente en países desarrollados del mundo occidental, donde hay un progresivo incremento de trastornos de la ingesta. Algunas de estas investigaciones nos dan indicios de cómo la influencia de los medios interactúa con la insatisfacción corporal para incrementar la probabilidad de los trastornos alimenticios.

Toro y Vilardel estudiaron la publicidad pro adelgazamiento incluida en 10 revistas femeninas españolas, las cuales constituían alrededor del $80 \%$ de todas las leídas por la población femenina durante los meses de mayo de 1984 y 1985. Analizaron todos los anuncios aparecidos en esas revistas y seleccionaron, los que de manera textual o por imágenes de mujeres jóvenes delgadas, incitaran al uso o consumo de productos destinados a adelgazar o hicieran deseable el adelgazamiento. Los resultados obtenidos demostraron lo siguiente: "casi uno de cada cuatro anuncios que llegan a un público predominantemente femenino invitan directa o indirectamente a perder peso o a ser deseable un peso bajo" (Toro y Vilardel, 1987: 121). Asimismo, observaron como en los anuncios se presentaba un cambio significativo en las razones para invitar a la pérdida de peso: el 55\% de los argumentos pro adelgazamiento eran estéticos y sólo el 19\% estaban relacionados con la salud (Toro y Vilardel, 1987: 124), es decir, vende más la motivación estética que la sanitaria.

La investigación realizada por Harrison y Cantor (1997) con 232 mujeres y 192 hombres, todos estudiantes universitarios y con un promedio de edad entre los 20 años trata la relación entre medios de comunicación (televisión y revistas) y los desórdenes alimenticios. Este estudio demostró en general que el consumo de los medios de comunicación predijo significativamente la sintomatología de los desórdenes de comida en las mujeres y las actitudes de los hombres a favor de su dieta personal y delgadez. Estos resultados fueron más consistentes en las respuestas sobre las lecturas de las revistas que la televisión. Las mujeres quienes leen las revistas no sólo por razones físicas o concernientes a la dieta, tienen un alto puntaje en el desorden de comidas, en relación con quienes raramente las leen.

El estudio de Young, McFattera y Clopton (2001) tuvo como objetivo determinar si el funcionamiento de la familia, la influencia del grupo de pares y la influencia de los medios de comunicación masiva son predictores adecuados del comportamiento bulímico. Estos investigadores trabajaron con un grupo de 120 mujeres estudiantes menores de 30 años. Llegaron a la conclusión que la influencia de los medios interactúa con la insatisfacción corporal para incrementar la probabilidad del comportamiento bulímico.

Hargreaves y Tiggemann (2004) examinaron el efecto expositivo de imágenes idealizadas de belleza sobre la imagen corporal a través de los medios en adolescentes australianos de ambos sexos (310 mujeres y 285 hombres). Este estudio concluyó que los comerciales con imágenes corporales idealizadas tienden a incrementar la insatisfacción corporal en mujeres, pero no en hombres; igualmente, estas provocan un incremento en el mal humor y la comparación de apariencias tanto para hombres como mujeres, aunque el efecto en la comparación de apariencias es mayor en el género femenino. Los y las participantes quienes invierten en cuidar su apariencia física reportaron una mayor conducta de comparación de apariencias luego de ver los comerciales idealizados, que aquellos y aquellas con menor tendencia 
a cuidar su apariencia. Las mujeres parecen procesar la información relativa a la apariencia de manera más automática y permanece más esta información en ellas que en el caso de los hombres.

Keery, Van den Berg y Thompson (2004) hacen una evaluación del Modelo de Influencia Tripartita (MIT), el cual propone que la imagen corporal y los problemas alimenticios son influidos por la presión de pares, padres y de medios de comunicación a través de los mecanismos de comparación e internalización. Para realizar la evaluación, cuentan con un grupo de 325 mujeres con edades entre los 11 y 15 años estudiantes de sexto, sétimo y octavo año en un colegio de la Florida. Determinaron como el MIT es adecuado y útil para entender el proceso que predispone a las mujeres a desarrollar perturbaciones de la imagen corporal y desórdenes alimenticios.

Un grupo de investigadores de la Universidad de Florida en Tampa (2005), Birkeland, Thompson, Herbozo, Roehrig, Cafri y Van den Berg, realizaron una investigación donde examinaron la relación entre la insatisfacción con la imagen corporal, el humor y la exposición a los medios de comunicación masiva. Evaluaron, además, la influencia de los productos y las modelos femeninos de anuncios de revistas en la visualización del esquema corporal propio. Participaron en esta investigación 138 mujeres universitarias. Concluyeron que variables como aflicción, insatisfacción física, depresión, enojo y baja autoestima se relacionan con la exposición de modelos femeninas atractivas en anuncios; es decir, la insatisfacción corporal se debe a un estímulo humano y no a un producto por sí solo.

Otro grupo de investigadores en Estados Unidos, Yamamiya, Cashb, Melnykb, Posavacc y Posavacd (2005), evaluaron los efectos de la internalización de imágenes ideales proyectadas en los medios de comunicación. El grupo de estudio lo constituyeron 123 mujeres estudiantes con edades entre los 18 y 29 años. Estas fueron expuestas a 20 imágenes de modelos de moda de distintas revistas y se utilizó, además, un estímulo control (20 imágenes de automóviles). Estos investigadores infirieron como las mujeres, cuyos niveles de internalización son altos se ven más expuestas a tener distorsiones en la imagen corporal luego de ver imágenes idealizadas.

En la población costarricense no hay estudios específicos sobre esta temática; empero algunos tratan aspectos relacionados. La investigación de Rivera (1999), sobre los desórdenes alimenticios en un grupo de 480 adolescentes de ambos sexos, señala como las mujeres presentan mayor preocupación que los hombres por su cuerpo y la forma de este. Asimismo, ellas reflejan mayor temor a engordarse. Esta preocupación tiende a asociarse con angustias subyacentes sobre el éxito, la aceptación social y la capacidad de controlar y dirigir la vida, cifrada en la propia corporalidad.

\section{ANÁLISIS DE LA PUBLICIDAD EN LA REVISTA PERFIL}

Se puede afirmar que en la sociedad costarricense no estamos ajenos a la problemática antes señalada $y$ es pertinente determinar sus alcances. Como respuesta a esta necesidad la Universidad de Costa Rica está iniciando un programa de investigación en este sentido, con poblaciones adolescentes por ser el período de mayor riesgo para sufrir insatisfacción corporal $y$ trastornos alimenticios, aunque estos trastornos abarcan las edades desde los 12 hasta los 25 años (Toro y Vilardel, 1987).

Como parte de estas investigaciones surge la necesidad de realizar un análisis sobre la publicidad incluida en una revista dirigida a mujeres, con el fin de cuantificar la presencia de anuncios que emiten mensajes relacionados con la imagen del cuerpo femenino y analizar las modelos que se utilizan en los anuncios.

Se está entendiendo la publicidad como el proceso de comunicación donde participan: un anunciante que paga la comunicación, un anuncio, un medio masivo el cual pretende llegar rápidamente a gran número de personas (en este caso una revista) y un público objetivo (mujeres). La publicidad pretende dar a conocer un producto, servicio, idea o institución con el objeto de informar o influir en su compra o aceptación (Ortega, 1999). 
Las revistas se caracterizan positivamente por: selectividad demográfica que se da, básicamente, la existencia de dos grupos de lectores (público femenino y masculino), la calidad de soporte, la flexibilidad de espacio y realización de publicidad mancomunada; además, mantienen cierta permanencia, incluso se pueden coleccionar. Poseen las desventajas de poca selectividad geográfica y limitada difusión y audiencia (Ortega, 1999).

Francisco Pérez (2000) considera que los medios impresos tienen mayor relevancia en el mercado actual y las revistas son un buen exponente de ello comparándolas, por ejemplo, con otros medios como la televisión, la cual ha aumentado los costos en el tiempo y la producción de los anuncios publicitarios; también, la fragmentación de las audiencias por la llegada del cable y el vídeo ha sido otro aspecto negativo. Asimismo, considera que las revistas presentan una evolución hacia spots más breves los cuales permiten una venta profunda y razonable, mientras en la televisión se hace cada vez más difícil. Igualmente, la diversificación de los medios impresos logran llegar a segmentos demográficos pequeños y eso permite a los anunciantes alcanzar audiencias mucho más especializadas y delimitadas con singular atractivo, como en este caso el grupo de mujeres.

Por otra parte en lo referente a la comparación entre revistas $y$ diarios, la excelente calidad de reproducción de las revistas ofrece mayor ventaja para la publicidad que los diarios, también, la presencia impresa relativamente larga (semanal, quincenal) en el mercado de lectores incrementa las posibilidades de ver el anuncio, se le da más atención y la lectura es más cuidadosa. El número de personas quienes leen cada ejemplar en hogares y lugares públicos es, por lo general, más elevado que el de los periódicos. Asimismo, los anuncios son parte de la configuración total que los lectores esperan encontrar cuando leen revistas, es decir, hay compatibilidad entre contenidos publicitarios y no publicitarios (Pérez, 2000).

Para el actual estudio se ha seleccionado la Revista Perfil, la cual salió al mercado costarricense en 1984. Actualmente, se distribuye quincenalmente durante diez meses al año $y$ en los restantes dos meses se edita una "Especial", es decir, en total se publican 22 ejemplares al año. Las consumidoras de esta Revista se identifican, en su mayoría, como mujeres entre los 18 y 45 años. Hoy, la Revista tiene un promedio de medio millón de lectores $y$ lectoras al mes (información brindada por la Coordinadora Editorial de la Revista Perfil, Thaís Aguilar Z. en noviembre 2005).

\section{ASPECTOS METODOLÓGICOS}

La investigación tiene un enfoque discursivo cuantitativo, se basa en el uso de la estadística para establecer patrones de comportamiento (Hernández, Fernández y Baptista, 2003). El tipo de estudio es un análisis de contenido diacrónico; el cual busca hacer un conteo preciso de sus características en el conjunto de una serie de mensajes para sistematizar los resultados y darlos a conocer con mayor economía (Valles, 1997).

El método de muestreo que se utilizó es no probabilístico, basado en el juicio del experto. No pretende la representatividad de los elementos de una población, sino una cuidadosa y controlada elección con ciertas características que corresponden al problema de la investigación (Hernández, Fernández y Baptista, 2003). La muestra abarca los dos últimos años editados de la revista hasta el momento de la investigación; del 2004 se seleccionaron 12 revistas, una por mes, $y$ del 2005 se analizaron 11, una por cada mes desde enero a noviembre. Se inició seleccionando la Revista de la primera quincena de enero del 2004, del mes siguiente se escogió la de la segunda quincena y así sucesivamente se fueron turnando la primera y segunda quincena. En total se trabajó con 23 ediciones.

Las variables fueron debidamente operacionalizadas y categorizadas para el procesamiento de la información que se realizó mediante el Paquete Estadístico para las Ciencias Sociales (SPSS) el cual utiliza el análisis de frecuencias $y$ porcentajes. 


\section{RESULTADOS}

\section{TIPO DE PRODUCTOS ANUNCIADOS}

En las 23 revistas analizadas hay un total de 871 anuncios. De estos casi la mitad (400) corresponden a productos y tratamientos físicos que llevan el mensaje de lucir más bellas, por ejemplo: cremas, cirugías, estética dental, cosméticos, tratamientos para adelgazar, etc. El resto de la publicidad corresponde a otros tipos de artículos que no tienen este fin.

Si bien un porcentaje significativo de los anuncios hacen referencia a determinados ideales de belleza femenina, se observó en los contenidos de la Revista Perfil una orientación a cuidar la salud física y mental de la mujer, pues muestra diversos artículos educativos que hacen conciencia en este sentido y fomentan la autoestima. Un artículo muy crítico es el de Thaís Aguilar (Revista Perfil, nro. 508, junio 2005: 10) donde señala que "Los cánones de belleza del mass media son imposibles de cumplir para cualquier mujer común y corriente, en cualquier parte del planeta”. Asimismo, hace referencia a que las modelos ideales inciden en el imaginario de las niñas y cita una investigación de Hayley Dohnt y Marika Tiggemann de la Universidad de Flinders (British Journal of Developmental Psycology, 2005), donde concluyen que el $71 \%$ de niñas escolares de 6 y 7 años aseguró desear una figura más delgada y el 45,7\% afirmó utilizar una dieta restrictiva si llegara a aumentar de peso; lo anterior refleja como las niñas están más preocupadas de su imagen corporal que de jugar con muñecas. La Coordinadora Editorial concluye que "... la belleza es una forma de tiranía que no nos deja en paz”.

\section{CATEGORÍA DE PRODUCTO ANUNCIADO}

Los 400 anuncios analizados se agrupan en categorías según el tipo de producto o tratamiento al que se refieren, como aparece en el gráfico siguiente:

\section{GRÁFICO 1}

PORCENTAJE DE LOS TIPOS DE PRODUCTOS ANUNCIADOS EN LA REVISTA

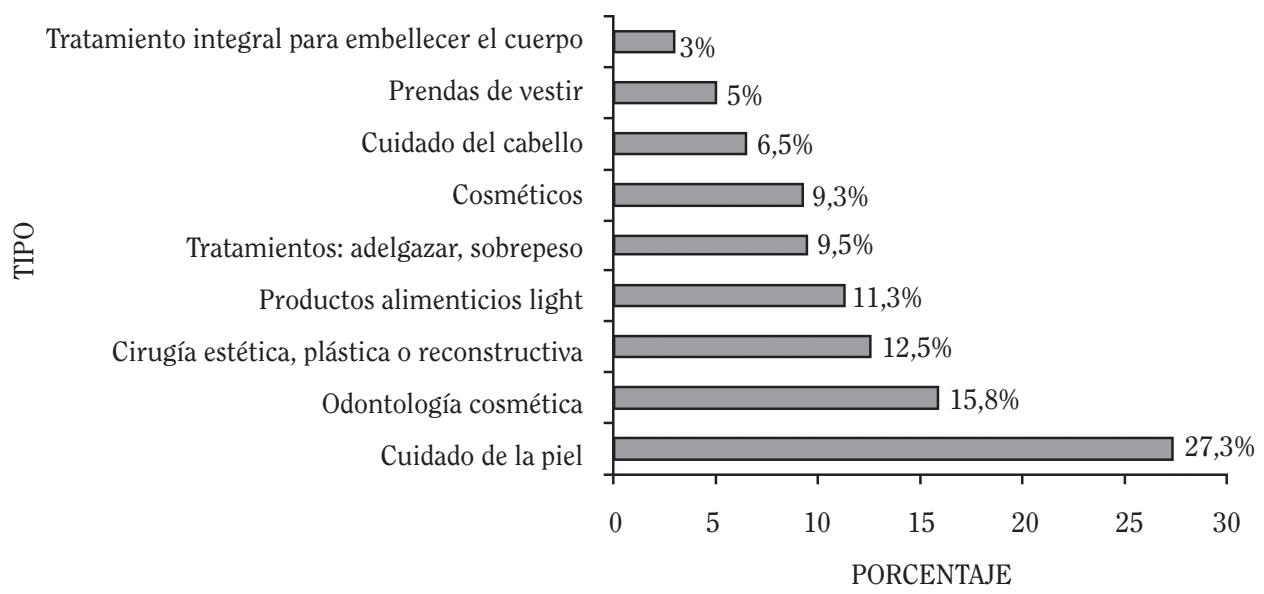

Analizando los productos publicitados se observa que el 36\% corresponde a artículos o prácticas para modificar el cuerpo y obtener una figura más acorde al patrón delgado que dicta la moda actualmente, tales como productos alimenticios light, cirugía estética, plástica o reconstructiva $y$ tratamientos para adelgazar e integrales para embellecer, que incluyen la pérdida de peso. Es aquí acorde el pensamiento de Thaís Aguilar (2005: 10) cuando expone que "La incidencia de cirugías plásticas parece constatar que la belleza natural está pasando de moda y que es la belleza construida y reconstruida la que vale". 
Por otro lado, se podría afirmar que el servicio odontológico no se publicitaba en épocas anteriores como lo hace ahora; pues también se observa que la odontología cosmética ocupa un porcentaje importante de anuncios en los cuales se utiliza no sólo un mensaje de salud sino de belleza con contenidos tales como

El caminar por la vida brindando una sonrisa no sólo sincera pero también hermosa puede abrir puertas en cualquier situación y lugar [o] la solución completa para sus problemas de estética y salud bucodental.

Es decir, el estándar de belleza ideal abarca, prácticamente, todas las partes del cuerpo humano. Por ejemplo, un anuncio de cirugía estética hace referencia a "Lipoescultura, aumento, reducción y levantamiento de senos, cirugía de nariz, rejuvenecimiento facial, aumento de glúteos, abdomen, orejas, párpados, mentón y botox".
De igual manera, la categoría de cuidado de la piel obtiene un porcentaje importante, principalmente donde se considera que los mensajes hacen referencia a "rejuvenecer", "reducir arrugas", "mantiene la piel bella, suave y fresca".

\section{TAMAÑO DEL ANUNCIO}

Los productos y tratamientos para embellecer gozan de un espacio significativo en la Revista como se puede ver en el gráfico 2 , la mayoría $(70 \%)$ ocupan media página 0 más. Esto nos da indicios de la alta inversión hecha por los anunciantes para vender sus productos o tratamientos. Lo anterior denota lo llamativo que resulta para las lectoras estos anuncios, pues ocupan espacios grandes, privilegiados, que permiten captar fácilmente su atención.

GRÁFICO 2

PORCENTAJE DEL TAMAÑO DE LOS ANUNCIOS DE LA REVISTA

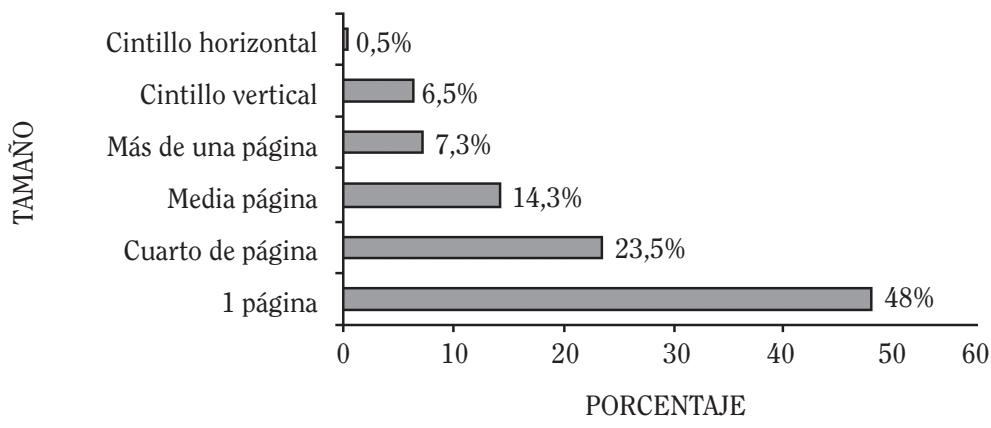

FONDO DE LOS ANUNCIOS

En el fondo de los anuncios predomina el diseño vacío, tipo estudio que se caracteriza por no tener elementos, lo cual da más realce $y$, por consiguiente, atención a la modelo y al producto. Como se observa en el gráfico 3, muy pocos anuncios presentan un campo interior donde descansan la modelo y el producto con elementos de fantasía (ficticios, ilusorios) o que corresponden a la realidad. 


\section{GRÁFICO 3}

\section{PORCENTAJE DE LOS TIPOS DE FONDO DE LOS ANUNCIOS DE LA REVISTA}

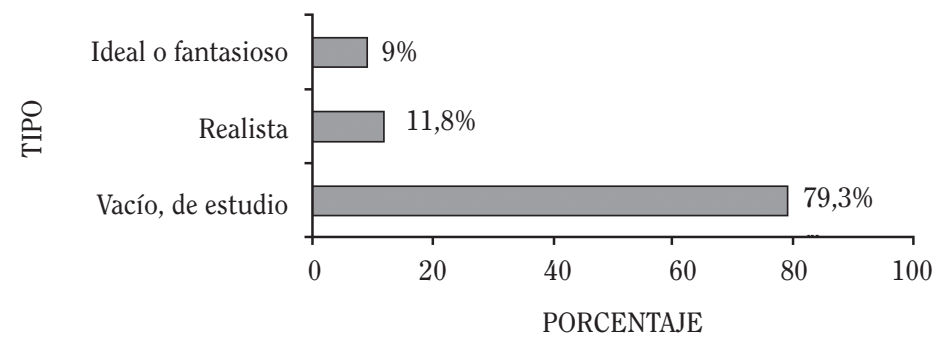

\section{ESTRATEGIA EXPOSITIVA}

Dentro de las estrategias publicitarias, González y Ortiz (1999) hacen la diferencia entre la retórica que corresponde a la articulación de una argumentación (es la menos utilizada en la publicidad de la Revista Perfil: $4,8 \%$, ver gráfico 4) y la seductora donde se presenta una imagen como texto icónico. Como lo plantean González y Ortiz, estos últimos son estímulos que escapan al campo de la información y significación y entran en el ámbito del deseo. Es así como “... cuanto más deseable resulta una imagen, tanto más se detiene en ella la mirada más allá del tiempo necesario para agotar su contenido informativo y significativo" (González y Ortiz, 1999: 15).

La seducción, por otro lado, responde a una función fáctica en la cual acentúa el contacto comunicativo entre el "Yo" (enunciador) y el "Tú" (enunciatario) no como figuras diferenciadas, sino como figuras fusionales. Además, en el discurso, el objeto, lo deseable, no está ahí, en cambio, en la interpelación seductora, el objeto deseable se hace presente.

Es así como el seductor se propone, de manera eficaz, como el objeto de deseo del seducido - "yo soy lo que tú deseas" — es decir, como el objeto identificatorio para el Yo del seducido. Y de esta forma las figuras del enunciador y del enunciatario, aun conservando sus posiciones formales - el uno habla y el otro escucha, el uno se muestra mientras el otro mira...(González y Ortiz, 1999: 22).
Ambas estrategias pueden combinarse $y$ coexistir en el interior de un mismo anuncio; sin embargo, la publicidad durante los últimos años, ha evolucionado al predominio de las seductoras y este mismo resultado se observa en el presente estudio, donde la mayoría de los anuncios, 95,2\%, muestran imágenes.

Para estos autores, las imágenes resultan identificatorias, seducen y capturan el yo del sujeto en una identificación imaginaria. Así, la presentación del producto y las modelos, en este caso, vienen a ser dispositivos seductores $y$, por ello, situados al margen de todo mecanismo cognitivo en el plano de lo imaginario, el cual alimenta los deseos de la y el espectador.

Por consiguiente, el spot se presenta como un discurso que habla persuasivamente del objeto, a la vez invita a un acto posterior de compra y utilización o consumo del mismo. Además, se usan otras series de operaciones que producen la asociación entre la imagen del objeto publicitario y la del actor del spot, observados en los anuncios estudiados; tales como la proximidad en la imagen (primeros planos), la mirada de las modelos dirigida al espectador y los modelos ideales acordes con la definición hecha por González y Ortiz (1999: 28)

Actores, por lo demás, de cuerpos perfectos, absolutamente deseables, inmunes al tiempo y sus erosiones (look), carentes de textura, descarnizados (light), absolutamente cerrados, plenamente imaginarios (lo real es plenamente lo que no cabe en el spot), que parecen no desear nada fuera de sí mismos (fantasías narcisistas extremas). 
GRÁFICO 4

PORCENTAJE DE ESTRATEGIAS PUBLICITARIAS DE LA REVISTA

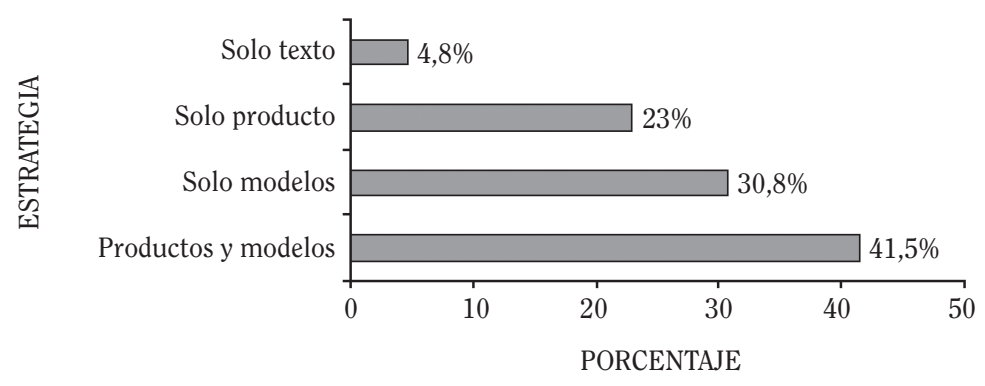

TIPO DE MODELO

Como se puede apreciar en el gráfico siguiente, la tendencia es presentar modelos de sexo femenino, esto se da en el 83,4\% de los comerciales; en muy pocos aparecen hombres, familias, parejas o niños. El emisor conociendo que la Revista está centrada en las mujeres, utiliza el espacio publicitario para presentar productos dirigidos a este grupo. Además, los anuncios seleccionados para el estudio corresponden a productos que buscan el cuidado personal y son mayormente utilizados por las mujeres.

\section{GRÁFICO 5}

PORCENTAJE DE LOS TIPOS DE MODELOS ANUNCIADOS EN LA REVISTA

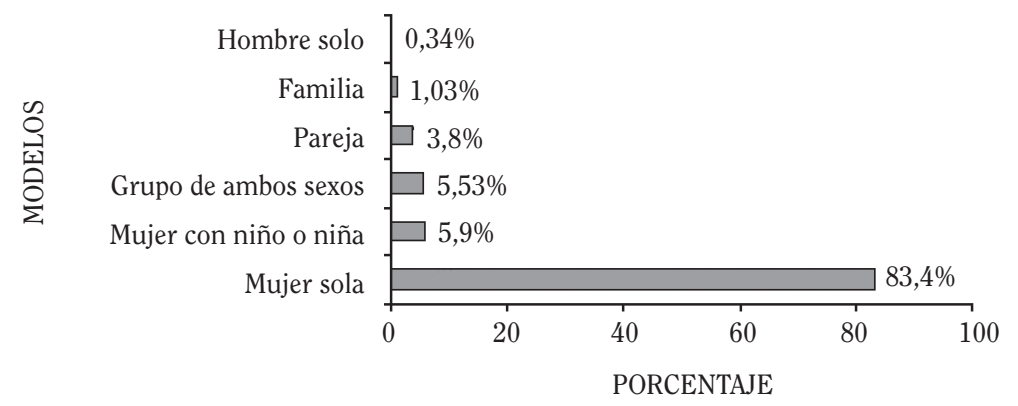

\section{PLANO EN QUE SE PRESENTAN LAS MODELOS}

El plano en que aparecen las y los modelos tienden a ser variados, sin embargo, más de una tercera parte se presentan de cuerpo entero (gráfico 6). Estas y estos modelos, por lo general son "delgadas(os)" y "flacas(os)" quienes se convierten en modelos deseables según González y Ortiz (1999). Los primeros planos dan la connotación de inmaculado, pleno y absoluto, lo cual logra una mayor identificación por parte del espectador. En muchos casos, este efecto se haya reforzado por la abstracción del fondo (79,3\%), donde se renuncia a la inserción de un contexto concreto. 


\section{GRÁFICO 6}

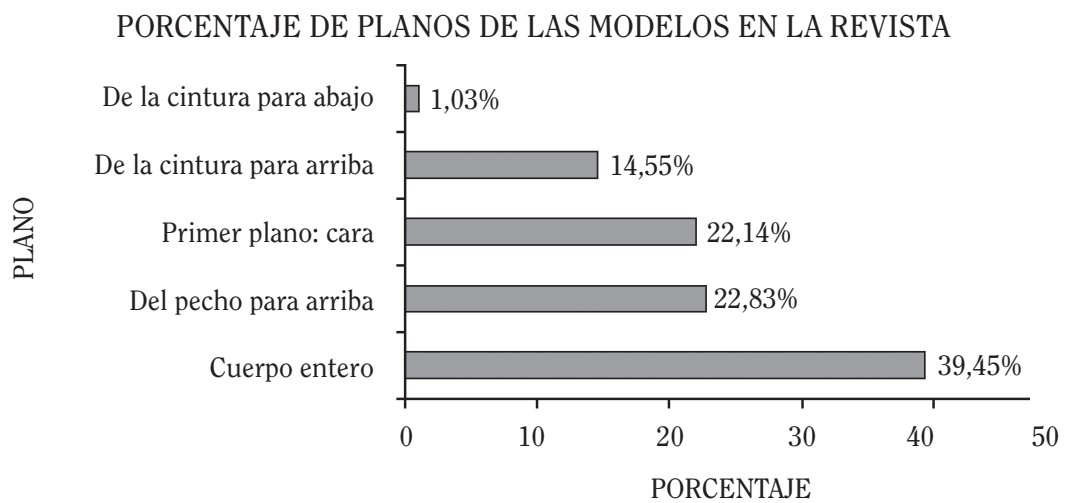

\section{VESTIMENTA DE LAS MODELOS}

La mitad de las y los modelos que aparecen en la publicidad de Perfil lucen su cuerpo desnudo o semidesnudo (gráfico 7) y en su mayoría es "delgado" o "flaco", figura deseada por la mujer en la sociedad actual. Este anhelo lo reconoce el emisor; puesto que lo usa como un recurso para llamar la atención del producto, reconocerlo como necesidad $y$ deseo y lograr mayor identificación con este.

\section{GRÁFICO 7}

PORCENTAJE DE LA VESTIMENTA DE LAS MODELOS EN LA REVISTA

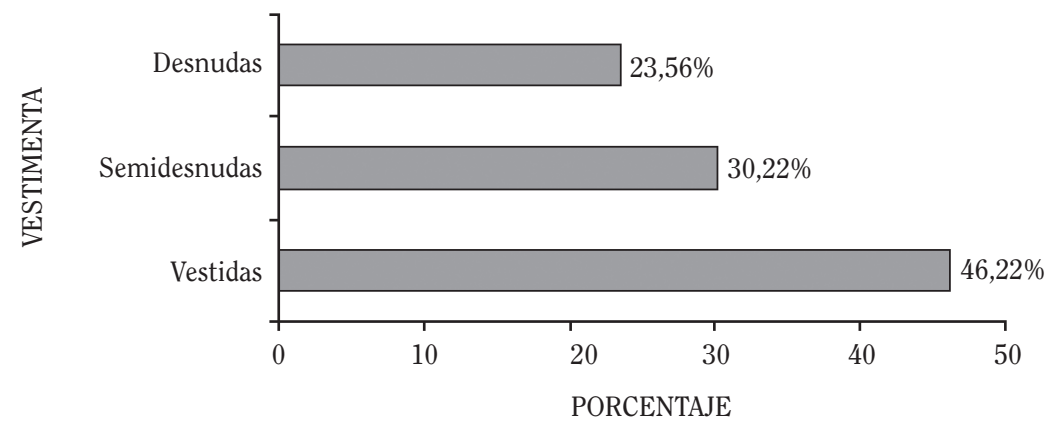

\section{ESTADO FÍSICO DE LAS MODELOS}

La gran mayoría de las modelos que aparecen en los anuncios $(77,5 \%)$ son "delgadas", y si sumamos las "flacas", el 93\% corresponden a los modelos femeninos denominados "tubulares" por Toro y Vilardel (1987) quienes están asociados con los trastornos alimenticios. Las fotos siguientes ejemplifican lo que se está considerando por modelos "delgadas", "flacas" y "gordas". 


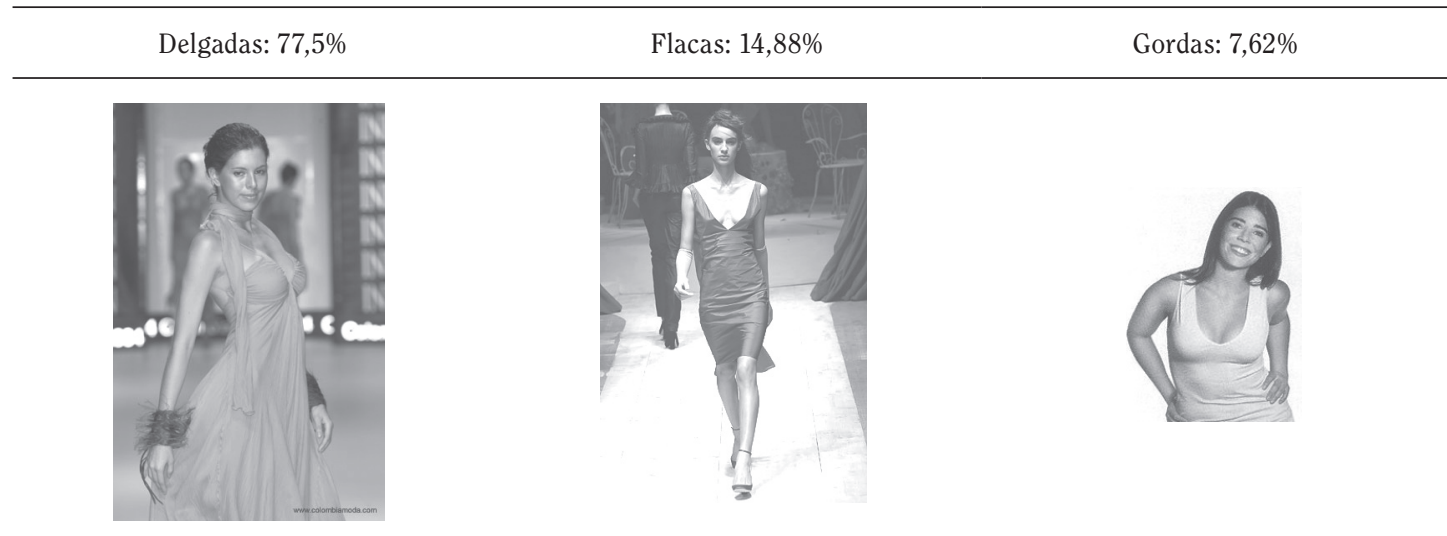

Tomado de la página de colecciones de moda, 7/3/06 www.beatrizcamacho. com

Tomada de la Revista Vogue. 22/2/06

_www.vogue.es/nuevas_pasarelas/
Tomada de DOVE, 22/2/06: www.porlabellezareal.com.ar/ Overview.asp?section=news
Las modelos que aparecen bajo la categoría de "gordas" representan básicamente la publicidad de Dove (compañía productora de cosméticos). Esta publicidad es denominada Campaña por la Belleza Real de Dove y tiene como objetivo

... cambiar el statu quo y ofrecer en su lugar una visión de la belleza más tolerante, más saludable y más democrática..., que todas las mujeres puedan tener $y$ disfrutar cada día (Etcoff, Orbach $y$ Scout, 2004:2).

La campaña se basó en un estudio emergido de la preocupación por la presencia de la belleza femenina en los medios masivos. Creen que la belleza femenina es altamente valorada $y$ representa una idea no auténtica ni alcanzable por la generalidad de las mujeres, lo cual puede impactar negativamente sobre su bienestar, felicidad $y$ autoestima.

La investigación de Dove fue dirigida en el 2004 por Nancy Etcoff (Universidad de Harvard), Susie Orbach (Escuela de Economía de Londres) y Jennifer Scout (investigadora de la empresa StrategtOne de New Cork). Se basó en una encuesta aplicada a 3200 mujeres de diez países (Estados Unidos, Canadá, Gran Bretaña, Italia, Francia, Portugal, Países Bajos, Brasil, Argentina y Japón). Los resultados señalan como las mujeres están de alguna manera satisfechas con su belleza un $58 \%$, atractivo físico 59\% y atractivo facial 58\%. Esta categoría "de alguna manera satisfecha" comprende mujeres que podrían estar "más felices" con su belleza y apariencia, aunque no son "infelices".

Por consiguiente, la investigación concluye que

... es posible que las mujeres de este grupo sean las más receptivas a los mensajes acerca de la belleza y la apariencia en los medios de comunicación y en la cultura popular porque, aunque obtienen alguna satisfacción de su apariencia, ciertamente creen que podrían estar más satisfechas (Etcoff, Orbach y Scout, 2004: 13). Solamente el 13\% de todas las mujeres están muy satisfechas con su belleza, el $12 \%$ con su atractivo físico, el $17 \%$ con su atractivo facial y el $13 \%$ con el peso $y$ forma de su cuerpo.

El estudio revela, además, como las mujeres ven a la belleza y al atractivo físico "altamente demandados y reconocidos socialmente", es decir, como la sociedad espera que: "las mujeres de hoy sean físicamente más atractivas que la generación de sus madres" (63\%) y que "las mujeres mejoren su atractivo físico" (60\%). Igualmente, el 45\% de todas las mujeres concordaron ampliamente en que "las mujeres más bellas tienen mayores oportunidades en la 
vida" y más de la mitad de las mujeres concuerdan en que "las mujeres físicamente atractivas son más valoradas por los hombres" (Etcoff, Orbach y Scout, 2004: 17).

\section{CONTENIDO DE LOS ANUNCIOS}

La gran mayoría de los anuncios emiten mensajes que van dirigidos a mejorar la figura física (cuadro 8). Algunos de estos directamente emiten el mensaje de reducir las medidas por medio de la cirugía o productos y tratamientos adelgazantes. Otros mensajes son más indirectos, hablan de rejuvenecer, lucir atractiva y estar a la moda con la presentación de modelos "delgadas" o "flacas", lo cual da indicios claros de la necesidad de consumir ese producto o tratamiento para lucir igual.

\section{GRÁFICO 8}

\section{PORCENTAJE DE LOS CONTENIDOS DE LOS MENSAJES EN LA REVISTA}

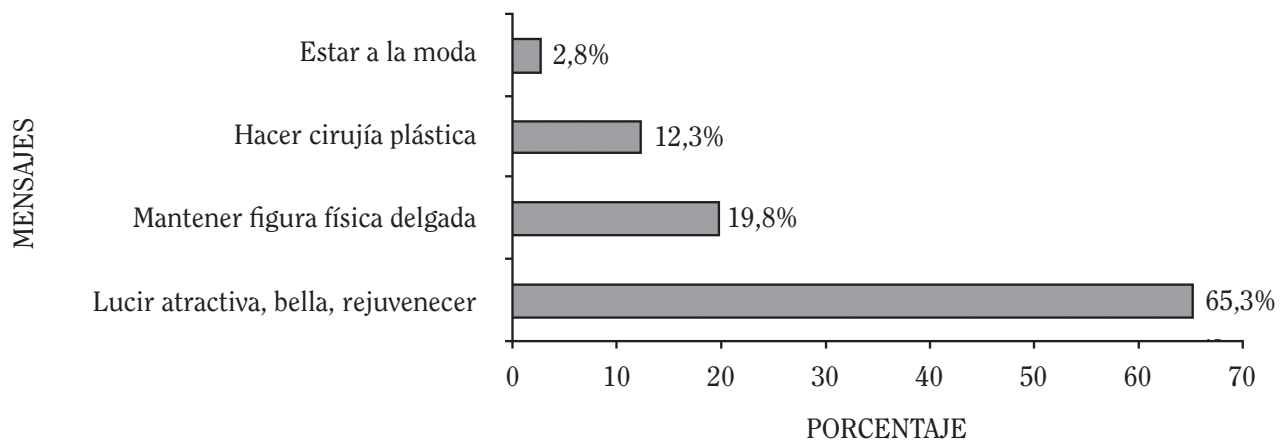

\section{CAMINO CREATIVO}

Luis Bassart (1994) define los caminos creativos básicos que pueden combinarse entre sí para lograr gran creatividad en la publicidad, dentro de estos se encuentran: los trozos de vida, la comparación, el problema solución, el testimonial, demostración y el símbolo visual. En el cuadro siguiente, se observa como la "demostración" y el "símbolo visual" (90\%) son las estrategias creativas más utilizadas en los anuncios de Perfil. La primera consiste en demostrarle al consumidor, de manera clara $y$ explícita, las ventajas racionales del producto, a través de: características, funcionamiento, aplicaciones prácticas, beneficios, etc. El protagonista es tanto el producto como los beneficios que representa para el usuario. Su enfoque puede ser positivo (mostrar lo que hace) o negativo (lo que puede evitar). El símbolo visual trata de expresar una idea visualmente para hacerla más memorable y duradera.

GRÁFICO 9

PORCENTAJE DE LOS CAMINOS CREATIVOS UTILIZADOS EN LA REVISTA

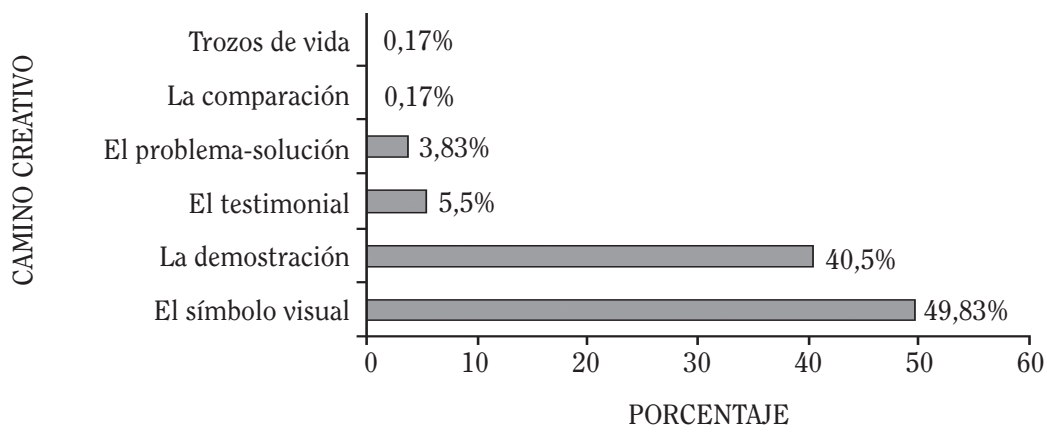




\section{DISCUSIÓN}

Los cánones de la sociedad actual, con respecto a las dimensiones corporales femeninas, ponen de moda la figura delgada $y$, como todo extremo, ni las mujeres "gordas" de moda en la época barroca, pintadas por Rubens, ni las "tubulares" de la época actual fueron o son las más sanas. Diversidad de investigaciones nos indican la problemática que vive la mujer al percibir en los medios de comunicación masiva, así como en las actitudes y comentarios de los individuos y grupos sociales, la ventajosa necesidad de ser "delgadas". No se puede obviar la influencia de estereotipos y valores estéticos culturales del cuerpo humano en la autoimagen de la mujer y las consecuencias de esta problemática, la cual afecta incluso a las niñas.

El análisis de la publicidad de Perfil permite apreciar como se fomenta un patrón estético corporal de mujer delgada y flaca, por medio de las modelos y los mensajes de belleza femenina publicados. Este estudio es un ejemplo, dentro de la gran variedad de revistas y medios tales como: televisión, vallas, afiches, carteles, rótulos en tapias y buses, mupis, empaques, internet, vídeos, películas, etc., donde las mujeres perciben diariamente los estereotipos estéticos bellos; incluso estos toman más fuerza cuando los personajes dan testimonio de sus logros, quedándole claro a la audiencia las ventajas de tener esa figura.

La revista, por sus características como medio de comunicación, constituye una fuente importante configuradora de la autoimagen del cuerpo femenino. En el caso de la publicidad de la Revista Perfil, se observa como diversos elementos contribuyen a que los mensajes sean tomados en cuenta. Es así como de cada 1,2 anuncios sobre artículos generales, uno invita a tener una figura más bella, lo cual implica en algunos casos modificar el cuerpo con alguna cirugía. Los anuncios son de color, llamativos, ocupan espacios grandes con fondos vacíos donde resaltan las modelos y el producto.

La estrategia expositiva es en su mayoría seductora, pues muestra al artículo o servicio acompañado de modelos femeninas, lo cual alimenta los deseos de la espectadora; presenta íconos y fotografías que se caracterizan por poseer mayor poder referencial; el proceso de codificación es instantáneo, casi imperceptible $y$ en algunos casos corresponde a personajes conocidos, lo que atrae y legitima el mensaje.

Asimismo, hay una estrecha relación entre el objeto anunciado y el consumidor potencial, en este caso la mujer. Se da la tendencia a establecer una relación entre el mensaje, personaje/objeto y el destinatario. El prototipo de personaje seleccionado tiende a representar las características principales del típico consumidor del producto, sus valores $y$ aspiraciones; en decir, el deseo de ser bella, delgada $y$, por consiguiente, aceptada. La mayoría de las modelos lucen cuerpos delgados y desnudos o semidesnudos donde se aprecia su estado; aparecen en primeros planos lo cual, sumado a la abstracción del fondo, logra mayor identificación por parte de las lectoras. De igual manera, las estrategias comunicativas empleadas resaltan los beneficios del producto $y$ hacen el mensaje más memorable y duradero.

De acuerdo con los mensajes emitidos por la publicidad de la Revista, podría decirse que el estado físico de las modelos las coloca en una situación ventajosa frente a las consumidoras. La belleza y el erotismo de las modelos actúan de un modo impactante y constituye un importante elemento de aspiración social, en pocas palabras, con la adquisición de determinados productos (cosméticos, cirugías, etc.) se consigue la belleza deseada. De manera directa e indirecta, los mensajes señalan la necesidad apremiante de modificar el cuerpo para lograr el estándar deseado que reflejan las modelos. Este ideal de belleza transmitido por los medios $y$, en este caso, por la publicidad de la revista Perfil puede ser unos de los factores que comprometen la salud emocional y física en las mujeres.

\section{REFERENCIAS BIBLIOGRÁFICAS}

Aguilar, Thaís. "La tiranía de la belleza". Revista Perfil: 508. San José. 2005, p.10.

Bassat, Luis. El libro rojo de la publicidad. Muntaner, España. Editorial Folio, SA. 1994. $120 \mathrm{p}$. 
Bryant, Jennings y Zillmann, Dolf. Los efectos de los medios de comunicación: investigaciones y teorías. Barcelona, España. Paidós Ibérica, 1996, p.670.

Birkeland, Robyn; Thompson, J. Kevin; Herbozo, Sylvia; Roehrig, Megan; Cafri, Guy y Van den Berg, Patricia. Media exposure, mood, and body image dissatisfaction: an experimental test of person versus product priming [en línea]. Body Image. 2005, vol. 2, nro.1, 53-61. Disponible en la base de datos Science Direct. <http:// www.sciencedirect.com> [Consulta: 2 de noviembre del 2005].

Etcoff, Nancy; Orbach, Susie y Scott, Jennifer. La verdad acerca de la belleza. Resultados del Estudio Global de Dove sobre las mujeres, la belleza y el bienestar [en línea]. Estados Unidos, 2004. Disponible en la Web <http://www.porlabellezareal. com.ar/overview.asp? section $=$ news $>$ [Consulta: 22 de febrero del 2006].

García, Norma Irene. "Trastornos de la conducta alimentaria en adolescentes de ambos sexos con y sin diabetes mellitus tipo 1". Tesis doctoral en Psicología de la Salud y Psicología Social de la Universidad Autónoma de Barcelona. 2004. Disponible en la Web <http://www.tdx.cesca.es/TESISUAB/ AVAILABLE/TDX-1215104-116515/nigrlde1. pdf $>$ [Consulta: 8 de setiembre del 2005].

González, Jesús; Ortiz, Amaya. El espot publicitario: Las metamorfosis del deseo. Madrid, España. Ediciones Cátedra. 1999, p. 175.

Hargreaves, Duane y Tiggemann, Marika. "Idealized media images and adolescent body image: 'comparing' boys and girls" [en línea]. Body Image, 2004, vol. 1, p. 351-361. Disponible en la base de datos Science Direct. <http://www.sciencedirect.com> [Consulta: 2 de noviembre del 2005].

Harrison, Kristen y Cantor, Joanne. "The Relationship between Media Consumption and Eating Disorders". Journal of Communication: vol. 47, nro.1, 1997, p. 40-67.

Hernández, Roberto; Fernández, Carlos y Baptista, Pilar. Metodología de Investigación. DF, México. Mc Graw-Hill Interamericana, 2003. p. 705.

Keery, Helen; Van den Berg, Patricia y Thompson, Kevin. An evaluation of the Tripartite Influence Model of body dissatisfaction and eating disturbance with adolescent girls [en línea]. Body Image, 2004, vol. 1, p. 237-251. Disponible en la base de datos Science Direct <http:// www.sciencedirect.com $>$ [Consulta: 2 de noviembre del 2005].

Ortega, Enrique. La comunicación publicitaria. Madrid, España. Ediciones Pirámide. 1999, p. 378.

Pearson, Judy C.; Turner, Lynn H. y ToddMancillas, W. Comunicación y género. Barcelona, España. Ediciones Paidós. 1993, p. 660.

Pérez-Latre, Francisco J. Planificación y gestión de medios publicitarios. Barcelona, España. Editorial Ariel. 2000, p. 173.

Rivera, Olga Marta. "Un estudio exploratorio de los desórdenes del apetito en una muestra de adolescentes del Área Metropolitana a través del Inventario para los desórdenes del apetito". Tesis para optar el grado de Licenciatura en Psicología. Universidad de Costa Rica. 1999, 112 p.

Saborit, José. La imagen publicitaria en televisión. Madrid, España. Ediciones Cátedra. 1994, p. 187. 
Toro, Joseph y Vilardell, Enric. Anorexia nerviosa. Barcelona, España. Ediciones Martínez Roca. 1987, p. 259.

Valles, Miguel. Diseños y estrategias metodológicas en los estudios cualitativos. Reflexión metodológica y práctica social. Madrid, España. Editorial Síntesis. 1997, p. 430 .

Yamamiya, Yuko; Cashb, Thomas; Melnykb, Susan; Posavacc, Heidi y Posavacd, Steven. "Women's exposure to thin-andbeautiful media images: body image effects of media-ideal internalization and impact-reduction interventions". [en línea]. Body Image, 2005, vol. 2, nro. 1, pp. 74-80. Disponible en la base de datos Science Direct $<$ http://www.sciencedirect.com> [Consulta: 2 de noviembre del 2005].

Young, Emily; McFattera, Robert y Clopton, James. Family functioning, peer influen$c e$, and media influence as predictors of bulimic behavior [en línea]. Eating Behavior, 2001, vol. 2, pp. 323-337. Disponible en la base de datos Science Direct <http://www.sciencedirect.com> [Consulta: 2 de noviembre del 2005]. 
